\title{
EFFECT OF WATER-TRAINING IN THE MAINTENANCE OF CARDIORESPIRATORY ENDURANCE OF ATHLETES
}

\author{
C. J. GATTI, MS, ${ }^{1}$ R. J. YOUNG, PhD, ${ }^{2 *}$ and H. L. GLAD, EdD ${ }^{3}$ \\ ${ }^{1}$ Dept. of Sports and Recreation, Cross Country Coach, Washington University, St. Louis, Missouri 63130 \\ ${ }^{2}$ Assistant Professor, Department of Physical Education, Washington University, St. Louis, Missouri 63130 \\ ${ }^{3}$ Pathway School District, Supervisor for Physical Education, St. Louis, Missouri 63017
}

\begin{abstract}
The effectiveness of water-training in maintaining cardiorespiratory endurance was investigated in 16 cross country athletes, 18-24 years. Following a competitive season, subjects were stress-tested $\left(T_{1}\right)$ and divided into three equated groups based on $\mathrm{VO}_{2}$ max. Group I $(n=5)$ continued training as it had during the competitive season. Group II (n=5) underwent an experimental period of water-training, and Group III $(n=6)$ let their training lapse. Subjects in the water-training group exercised in deep water for $\mathbf{4 0}$ minutes, $\mathbf{6}$ days/week for $\mathbf{3}$ weeks, supported by a flotation device which permitted them to engage in a running type activity, resembling their natural running form. All subjects were retested after 3 weeks $\left(T_{2}\right)$. A non-significant $F$ ratio from an analysis of variance at $T_{1}$ confirmed the equality of the three groups in terms of $\mathrm{VO}_{2}$ max. Analysis of covariance at $\mathrm{T}_{2}$ using $\mathrm{T}_{1} \mathrm{VO}_{2}$ max values as covariates revealed a significant $(p<.05) \mathrm{F}$ ratio reflecting a significant $(p<.05)$ difference between the regular training group and the group which let its training lapse. The water-training group did not differ significantly from the regular training group indicating that the water-training programme prevented a significant decline in $\mathrm{VO}_{2}$ max.
\end{abstract}

\section{INTRODUCTION}

Injuries caused by overuse or overtraining are a major problem in competitive sports and a variety of methods, including swimming and cycling, have been employed by athletes to maintain cardiorespiratory fitness while they are unable to follow their regular training regimen. $A$ relatively recent method is that of water-training (Buss, 1976) in which the injured athlete runs through deep water supported by a flotation device using as close to normal running style as possible. The purpose of this study was to investigate the effectiveness of the watertraining method in maintaining $\mathrm{VO}_{2}$ max in a group of first year cross country athletes.

\section{METHODS}

\section{Subjects}

Sixteen male members of the Washington University cross country team, $18-24$ years, volunteered to participate in this study. Following the competitive season they took a graded exercise test $\left(T_{1}\right)$ and on the basis of $\mathrm{VO}_{2}$ max scores, were divided into three equated treatment goups. Group I $(n=5)$ continued training as it had during the season. Group II $(n=5)$ underwent an experimental period of water-training, and Group III $(n=6)$ discontinued training. After three weeks the subjects were retested $\left(\mathrm{T}_{2}\right)$ to determine $\mathrm{VO}_{2}$ max levels. All training sessions prior to commencement of the study

\footnotetext{
* At present Director of Preventive Medicine with Edward J. Funk and Sons, Inc., Kentland, Indiana 47951.
}

were supervised by the principal author, as were all sessions of water-training. Subjects were advised not to participate in other activities involving strenuous physical exercise during the period of study.

\section{Determination of $\mathrm{VO}_{2} \max$}

Maximal oxygen uptake was determined using the modified Åstrand-Saltin treadmill test (1967). Before actual testing, each subject exercised on a Collins variable speed treadmill to become acclimatized to the machine and to determine the appropriate speed and grade to be used during testing. On the test days, subjects warmed up by running on the treadmill for 10 minutes at $8 \mathrm{mph}$ and $3 \%$ grade. This was followed by a 5 minute rest period. The subject then ran for 5 minutes at $10 \mathrm{mph}$ at $3 \%$ grade. When necessary, the speed and grade were adjusted according to the results of the initial test. Expired air was collected during the 4th and 5th minute using a Douglas bag. Subjects rested for 10 minutes while the volume of the expired air was determined. The percent $\mathrm{O}_{2}$ and $\mathrm{CO}_{2}$ were determined using mass spectrometry.

Subjects then performed a second 5 minute trail at 10 $\mathrm{mph}$ and $5 \%$ grade. Expired air was again collected and analyzed as described above. The highest $\mathrm{VO}_{2} \max$ value was used in the statistical analysis.

\section{Water-Training}

Group II trained in the deep end of the University's pool for $\mathbf{4 0}$ minutes, 6 days/week for a period of 3 weeks. Subjects were supported by a flotation device, so that 
their bodies were essentially vertical, permitting them to engage in a running type activity resembling their natural running form. Every other day the workout was a steady paced "run through the water" during which the subject counted his own heart rate at various intervals by palpating the carotid artery. Heart rates attained during these training sessions ranged from 135-140 beats/minute. On the other training days each subject ran a paced run through the water for 20 minutes followed by 20 minutes of interval training. These intervals consisted of 2 minutes of hard running followed by 2 minutes of easy running ( 5 of each, for a total of 20 minutes). Immediately following each interval, the subject noted his heart rate and attempted to run at a pace which raised it to at least 160 beats/minute. The easy run between intervals elicited a heart rate of approximately 125 beats/minute.

\section{Statistical Analysis}

The analysis of variance technique was used to determine significant differences, if any, among the $\mathrm{VO}_{2}$ max means of the three groups at $T_{1}$. At $T_{2}$, an analysis of covariance was performed using $\mathrm{T}_{1} \mathrm{VO}_{2} \max$ values as covariates.

\section{RESULTS}

The physical characteristics of each group are presented in Table I.

\section{TABLE 1}

Physical characteristics of each group (Mean \pm S.E.)

$$
\begin{aligned}
& \text { Regular } \\
& \text { Training }
\end{aligned}
$$

$\begin{array}{lrrr}\text { Age (yrs) } & 22.6 \pm 0.9 & 19.8 \pm 0.6 & 20.7 \pm 0.7 \\ \text { Height (cms) } & 174.1 \pm 2.6 & 178.5 \pm 3.2 & 176.3 \pm 2.8 \\ \text { Weight (kgs) } & 68.5 \pm 2.6 & 64.0 \pm 2.2 & 69.1 \pm 4.9\end{array}$

The $T_{1}, T_{2}$ and adjusted $T_{2} V O_{2}$ max means for each group are presented in Table II.

TABLE 2

$\grave{V O}_{2} \max (\mathrm{ml} / \mathrm{kg} / \mathrm{min})$ means at $T_{1}$ and $T_{2}$

$\begin{array}{llll} & \begin{array}{l}\text { Regular } \\ \text { Training }\end{array} & \begin{array}{l}\text { Water- } \\ \text { Training }\end{array} & \begin{array}{l}\text { Discontinued } \\ \text { Training }\end{array} \\ \mathrm{T}_{1} & 59.4 \pm 1.5 & 59.2 \pm 2.5 & 58.1 \pm 2.3 \\ \mathrm{~T}_{2} & 57.5 \pm 0.8 & 54.8 \pm 1.8 & 52.5 \pm 1.8 \\ \text { Adjusted } \mathrm{T}_{2} & 57.2 \pm 1.0 & 54.6 \pm 1.0 & 52.9 \pm 0.9\end{array}$

The results of the $T_{1}$ analysis of variance are presented in Table III. No significant differences were found among the groups confirming their equality in terms of $\mathrm{VO}_{2}$ max level.

TABLE 3

$$
\text { Analysis of Variance of } \mathrm{VO}_{2} \max \text { at } \mathrm{T}_{1}
$$

$\begin{array}{lrrr}\text { Source } & \text { d.f. } & \text { M.S. } & \text { F } \\ \text { Between } & 2 & 3.11 & .12 \\ \text { Within } & 13 & 25.14 & \end{array}$

\section{TABLE 4}

Analysis of covariance of $\mathrm{VO}_{2} \max$ at $\mathrm{T}_{2}$

$\begin{array}{lrr}\text { Source } & \text { d.f. } & \text { M.S. } \\ \text { Between } & 2 & 24.39 \\ \text { Within } & 12 & 5.11 \\ & & \\ \text { "p }<0.05 & & \end{array}$

The results obtained from the analysis of covariance on the $T_{2}$ data (Table IV) revealed a significant difference $(p<.05)$ among the groups. When the adjusted means representing each group were analysed by the Newman-Keuls procedure, the regular training group $(57.18 \pm 1.01)$ and the group which discontinued training $(52.94 \pm 0.93)$ differed significantly $(p<.05)$. The water-training group $(54.57 \pm 1.01)$ did not differ significantly from the regular training group.

\section{DISCUSSION}

The effects of endurance training on cardiorespiratory fitness have been well documented (Pollock, 1973) and clearly shown to be related to intensity, frequency and duration (Davies and Knibbs, 1971; Gettman, et al, 1976; Milesis, et al, 1976; Olree, et al, 1969; Pollock, et al, 1977). Several studies have attempted to ascertain how much exercise is required to maintain $\mathrm{VO}_{2}$ max. For example, Liang, et al (1977) found that active students who exercised at $60 \%$ of $\mathrm{VO}_{2}$ max (mean $\mathrm{HR}=150$ beats/minute) with a duration of $45-60$ minutes, 3 sessions/week were able to maintain $\mathrm{VO}_{2}$ max at their initial level. In contrast, intensities of $\mathbf{4 0}$ to $60 \%$ with 15 to 30 minute duration appeared to have a negative effect on the cardiorespiratory parameters. Chaloupka and Fox (1975) found that frequency of exercise could be reduced using interval training while maintaining the same benefits. Similarly, Brynteson and Sinning (1973) showed that gains made in $\mathrm{VO}_{2} \max$ following a 5 day/week, 5 week training programme could be maintained by training only 3 days/week.

In this study there was no difference in $\mathrm{VO}_{2} \max$ between the three groups at $T_{1}$. This was to be expected 
since the groups were matched on the basis of $\mathrm{VO}_{2} \max$. When they were compared after the three week experiment $\left(T_{2}\right)$ the group which discontinued training had decreased significantly but the water-training group did not differ significantly from the group that continued regular training. The water-training programme therefore was of sufficient intensity, frequency and duration to prevent a significant drop in $\mathrm{VO}_{2} \max$ level. However, since the number of subjects in each group was very small, eventual confirmation of these findings will require the use of large numbers of subjects.

Several studies have noted the physiological effects of a lapse in training (Drinkwater and Horvath, 1972; Fringer and Stull, 1974; Michael, et al, 1972; Smith and Stransky, 1976; Taylor, et al, 1949). Michael, et al (1972) found that two months after the cessation of training the cardiorespiratory adaptations made during a conditioning period were essentially lost. Smith and Stransky (1976) found that 7 weeks of bicycle training at $73 \%$ of $\max$. HR range 16 minutes/day, 3 days/week resulted in significant gains in cardiovascular efficiency, but after letting training lapse for 7 weeks all subjects approached initial levels. Taylor, et al (1949) found that the $\mathrm{VO}_{2}$ max of students confined to bed for 3 weeks declined by $17 \%$. In this study the group which discontinued training declined by $9 \%$ after 3 weeks and at $\mathrm{T}_{2}$ had a significantly ( $\mathrm{p}<.05$ ) lower $\mathrm{VO}_{2}$ max than the group regularly exercising.

The subjects in the water-training group indicated that they felt that the water training method was effective in keeping them in condition. Such perceptions may be crucial in the rehabilitation of an injured athlete; however, it should be noted that the experimental subjects were not suffering from any injury at the time of the study. We might speculate, however, that if an athlete's injury does not prohibit the type of water exercises described in this paper, the decline in $\mathrm{VO}_{2}$ max associated with the interruption of regular training can be minimized.

\section{ACKNOWLEDGEMENTS}

The authors wish to express their gratitude to Drs. James Hagberg and Ollie Ehsani; Irene Walter Johnson Rehabilitation Center, Washington University Medical School, St. Louis, for their valuable technical assistance.

\section{REFERENCES}

Brynteson, P. and Sinning, W. 1973. "The Effects of Training Frequencies on the Retention of Cardiovascular Fitness". Med.Sci.Sports 5: 29-33.

Buss, R. 1976. "Keeping the Injured Athlete Fit". Track Technique 63: 2001.

Chaloupka, E. and Fox, E. 1975. "Physiological Effects of Two Maintenance Programs Following Eight Weeks of Interval Training". Fed.Proc. 34: 443.

Davies, C. T. M. and Knibbs, A. V. 1971. "Training Stimulus: Effects of Intensity, Duration and Frequency of Effort on Maximum Aerobic Power Output". Int.Z.Angew.Physiol. 29: 299-305.

Drinkwater, B. L. and Horvath, S. M. 1972. “Detraining Effects on Young Women”. Med.Sci.Sports 4: 91-95.

Fringer, M. N. and Stull, G. A. 1974. "Changes in Cardiorespiratory Parameters During Periods of Training and Detraining in Young Adult Females". Med.Sci.Sports 6: 20-25.

Gettman, L. R., Pollock, M. L., Durstine, J. L., Ward, A., Ayres, J. and Linnerud, A. C. 1976. “Physiological Responses of Men to 1, 3 and 5 Day Per Week Training Programs". Res.Quart. 47: 638-646.

Liang, M. T. C., Alexander, J. F., Taylor, H. L., Serfass, R., Leon, A. S. and Goldman, A. 1977. “Intensity and Duration of Exercise as Determinants of Cardiorespiratory Fitness". Proceedings of the American College of Sports Medicine..

Michael, E., Evert, J. and Jeffers, K. 1972. "Physiological Changes of Teenage Girls During Five Months of Detraining". Med.Sci.Sports 4: 214-218.

Milesis, C. A., Pollock, M. L., Bah, M. D., Ayres, J. J., Ward, A. and Linnerud, A. C. 1976. “Effects of Different Durations of Physical Training on Cardiorespiratory Function, Body Composition, and Serum Lipids". Res.Quart. 47: 716-725. 
Olree, H. D., Corbin, B., Penrod, J. and Smith, C. 1969. "Methods of Achieving and Maintaining Physical Fitness for Prolonged Space Flight". Final report to NASA Grant No. NGR-04-002-004.

Pollock, M. J. 1973. "The Quantification of Endurance Training Programs". In Exercise and Sport Sciences Reviews Vol. 1 pp. 115-188 Ed. J. Wilmore. Academic Press, New York.

Pollock, M. L., Gettman, L. R., Milesis, C. A., Bah, M. D., Durstine, L. and Johnson, R. B. 1977. "Effects of Frequency and Duration of Training on Attrition and Incidence of Injury". Med.Sci.Sports 9: 31-36.

Saltin, B. and Åstrand, P. O. 1967. "Maximal O, Uptake in Athletes". J.Appl.Physiol. 23: 353-358.

Smith, D. P. and Stransky, F. W. 1976. "The Effect of Training and Detraining on the Body Composition and Cardiovascular Response of Young Women to Exercise". J.Sports Med.Phys. Fitness 16: 112-120.

Taylor, H. L., Herschel, A., Brozek, J. and Keyes, A. 1949. "The Effect of Bed Rest on Cardiovascular Function and Work Performance". J.Appl.Physiol. 2: 223-239.

\section{MEETINGS OF OTHER ORGANISATIONS}

\section{SYMPOSIUM ON PHYSICAL TRAINING IN HEALTH PROMOTION AND MEDICAL CARE}

Kuopio University, and the Finnish Physiological Society and

Society for Research in Sport and Physical Education

August 6th -8 th, 1980

Communications are invited for this symposium, designed to bring together both from Finland and other countries results of research on the effects of physical training on common health problems. The programme will consist of invited papers and free communications, and the official language will be English. It is intended to publish the proceedings in book form. The deadline for submission of abstracts is March 31st, 1980, and they should be typed on the appropriate form, obtainable from the organisers. A programme for accompanying guests is arranged. Hotel reservations should be made through the organisers before June 30 th.

PARTICIPATION FEE: $\$ 100$ (or $\$ 120$ for late applications - after June 30th, 1980)

\section{PROGRAMME:}

Wednesday, August 6th

In the afternoon:

Thursday

In the afternoon:

Friday
Physiology of physical training. Speakers include Drs. J. Durnin, P. Cerretelli, M. Härkönen and P. Komi.

Tests of exertion and training systems; K. Lange Andersen, K. Cooper, D. Kabisch, H. Tiik, and a team from the USSR Research Institute of Physical Culture.

Obesity, Diabetes and Exercise. Drs. P. Björntorp, J. Parizkova, V. Koivisto, O. Siitonen, R. Rauramaa and K. Kukkonen.

R. Shepherd, and free communications.

D. Dorossiev, M. Karvonen, J. Huttunen, I. Vuori, J. Boyer, M. Harri, E. Länsimies, and free communications. The whole day will be devoted to cardiovascular diseases and exercise.

Applications and Enquiries to:

Dr. KATRIINA KUKKONEN,

Dept. of Physiology, University of Kuopio - PO Box 138,

SF - 70101 KUOPIO - 10, Finland

(Notice of this symposium received by BASM - November 16th, 1979) 